\title{
In vitro gentamicin release from commercially available calcium-phosphate bone substitutes influence of carrier type on duration of the release profile
}

\author{
Hein P Stallmann ${ }^{1,2}$, Chris Faber ${ }^{1,2}$, Antonius LJJ Bronckers ${ }^{2}$, Arie V Nieuw \\ Amerongen $^{3}$ and Paul IJM Wuisman*1
}

\begin{abstract}
Address: ${ }^{1}$ Orthopaedic Surgery, VU Medical Center, PO Box 7057, 1007 MB Amsterdam, The Netherlands, ${ }^{2}$ Oral Cell Biology / ACTA. vd Boechorststraat 7, 1081 BT Amsterdam, The Netherlands and ${ }^{3}$ Oral Biochemistry / ACTA, vd Boechorststraat 7, 1081 BT Amsterdam, The Netherlands

Email: Hein P Stallmann - h.stallmann@vumc.nl; Chris Faber - christopherfaber@zonnet.nl; Antonius LJJ Bronckers - a.bronckers@vumc.nl; Arie V Nieuw Amerongen - a.vannieuwamerongen@vumc.nl; Paul IJM Wuisman* - orthop@vumc.nl

* Corresponding author
\end{abstract}

Published: 26 February 2006

BMC Musculoskeletal Disorders2006, 7:18 doi:10.1186/147I-2474-7-18

This article is available from: http://www.biomedcentral.com/I47/-2474/7//8

(c) 2006Stallmann et al; licensee BioMed Central Ltd.

This is an Open Access article distributed under the terms of the Creative Commons Attribution License (http://creativecommons.org/licenses/by/2.0), which permits unrestricted use, distribution, and reproduction in any medium, provided the original work is properly cited.
Received: II May 2005

Accepted: 26 February 2006

\begin{abstract}
Background: Polymethyl-methacrylate (PMMA) beads releasing antibiotics are used extensively to treat osteomyelitis, but require surgical removal afterwards because they do not degrade.

Methods: As an alternative option, this report compares the in vitro gentamicin release profile from clinically used, biodegradable carrier-materials: six injectable cements and six granule-types. Cement cylinders and coated granules containing $3 \%$ gentamicin were submerged in $\mathrm{dH}_{2} \mathrm{O}$ and placed in a 48-sample parallel drug-release system. At regular intervals $(30,90,180 \mathrm{~min}$. and then every $24 \mathrm{~h}$, for $2 \mathrm{l}$ days), the release fluid was exchanged and the gentamicin concentration was measured. The activity of released gentamicin was tested on Staphylococcus aureus.
\end{abstract}

Results: All combinations showed initial burst-release of active gentamicin, two cements had continuous-release (17 days). The relative release of all cements (36-85\%) and granules (30-62\%) was higher than previously reported for injectable PMMA-cements (up to $17 \%$ ) and comparable to other biodegradable carriers. From the cements residual gentamicin could be extracted, whereas the granules released all gentamicin that had adhered to the surface.

Conclusion: The high release achieved shows great promise for clinical application of these biodegradable drug-carriers. Using the appropriate combination, the required release profile (burst or sustained) may be achieved.

\section{Background}

Osteomyelitis is a refractory condition, potentially leading to amputation or even death; treatment often requires multiple surgical interventions and local or systemic antibiotic therapy [1]. It predominantly affects both extremes of age; acute hematogenous infection occurs mainly in children and chronic osteomyelitis in the elderly [2]. Chronic osteomyelitis often requires surgical debridement and local antibiotic treatment. Disadvantages of currently used non-biodegradable polymethyl-methacrylate (PMMA) carriers include low antibiotic release by cements and the requirement of surgical removal in the 
case of PMMA-beads [3]. Moreover, resistant bacteria may appear on the carrier-surface during later stages of lowlevel antibiotic release [4]. In contrast, biodegradable antibiotic carriers may result in high release and obviate the need for removal; they are gradually replaced by ingrowing tissue $[5,6]$. Furthermore, secondary release of the antibiotic may occur during the degradation phase of the carrier, this could increase the antimicrobial efficacy compared to non-biodegradable carriers [7].

To our knowledge, this is the first study to describe in vitro antibiotic-release from twelve clinically available biodegradable carriers. The release profile of the drug-carrier combination determines the clinical efficacy for an important part. For prevention of infection, a high initial burst-release has been suggested, whereas treatment of chronic infection may require a sustained antibiotic-concentration $[3,8]$. The materials used, six injectable cements and six pre-shaped granule types, are all calciumphosphate based bone-defect fillers, mainly for nonweight-bearing applications. The chemical composition of these materials is highly similar to natural bone; all consist of calcium-phosphate ceramics and are slowly replaced by ingrowing bone [9].

\section{Methods}

\section{Sample production}

Gentamicin-sulphate (GS) loaded cements were produced by mixing cement powder and liquid containing $30 \mathrm{mg}$ GS (Biomet Merck BioMaterials, Darmstadt, Germany) per gram powder (liquid-powder-ratio according to the manufacturer). Cylinders hardened overnight $\left(37^{\circ} \mathrm{C}\right)$ in 6 $\times 5 \mathrm{~mm}$ molds. The cements were: Biobon (Biomet Merck BioMaterials), Calcibon (Biomet Merck BioMaterials), Biofil, (DePuy CMW, Blackpool, UK), Bonesource (Stryker-Leibinger, Freiburg, Germany), Chronos Inject, (Synthes, Bettlach, Switzerland) and Norian SRS (Synthes).

One gram of granules was immersed in $2.0 \mathrm{~mL}$ of $\mathrm{dH}_{2} \mathrm{O}$ containing $30 \mathrm{mg}$ GS per gram carrier-material and freezedried. After removal of the granules, the residual GS in the vessel was measured. The granules were: Allogran-R (Orthos, Bristol, UK), Bicalphos (Medtronic, Memphis, TN, USA), Biosorb (Science for Biomaterials, Lourdes, France), Bonesave (Stryker-Leibinger), Cerasorb (Curasan, Kleinostheim, Germany) and Vitoss (Orthovita Malvern, PA, USA).

\section{Release experiment}

As in previous experiments $[10,11]$, specimens were immersed in $500 \mu \mathrm{L} \mathrm{dH_{2 }} \mathrm{O}$, in sealed polystyrene 48-well plates (Costar, High Wycombe, UK) at room temperature on a shaking device (180 rpm). The water was replaced regularly: 30, 90 and 180 minutes on day 1 , and then 24

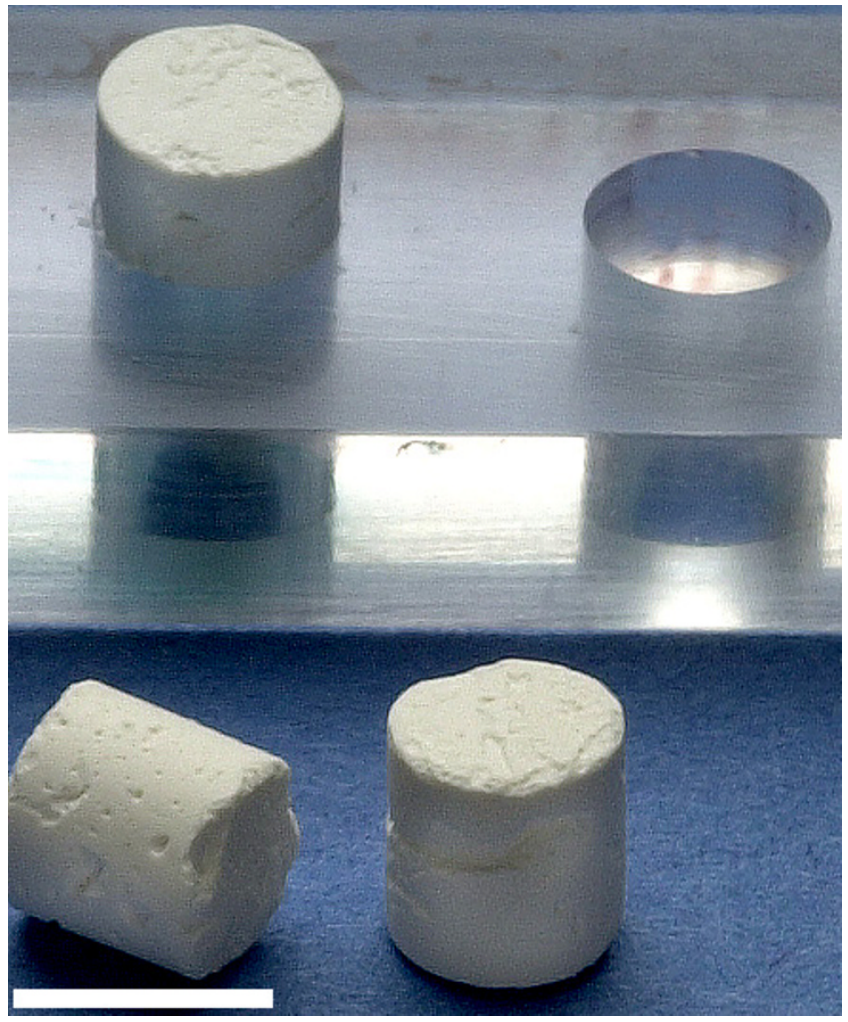

Figure I

Production mold and CaP cylinders $6 \times 5 \mathrm{~mm}(\mathrm{~A})$; the cylinders are slightly conical to facilitate extrusion. The scale bars are 5 $\mathrm{mm}$

hourly for 21 days (cements) or five days (granules) and stored at $-20^{\circ} \mathrm{C}$. Additional time points were used in the first 24 hours in order to detect a possible burst-release pattern. Immediately after the sample-production (control) and after the release experiment (residual) three specimens per group were finely ground and suspended in $4 \mathrm{~mL} \mathrm{dH}_{2} \mathrm{O}$ containing $1 \mathrm{M} \mathrm{NaCl}$ to determine the extractable amounts of GS. The cumulative release on day 21 (cements) or five (granules) was compared with Student's $t$-test (two-tailed, $\mathrm{p}<0.05$ ).

\section{Gentamicin determination}

Gentamicin concentrations were measured using an AxSym System (Abbott Laboratories, Irving, TX, USA), which allows accurate measurement of 0.30 to $30.00 \mu \mathrm{g} /$ $\mathrm{mL}$. Aliquots were therefore diluted in phosphate buffered saline (PBS); the values reported were corrected for the dilution factor. All measurements were calculated as GS quantities for transparent comparison to the amount of powder added during production. The accuracy was calculated as $2.9 \%$ (mean error of true value) and the precision as $1.6 \%$ (coefficient of variance), it was sensitive to $0.27 \mu \mathrm{g} / \mathrm{mL}$ with $95 \%$ confidence [7]. The values represent the mean \pm S.D. from three experiments, totalling at least 
Table I: All carriers combined high cumulative release with intact antimicrobial activity, only the cements had residual GS after release. The total release is also given as percentage of the $30 \mathrm{mg} / \mathrm{g}$ that was added during production. (a)Total release from three high release cements (Biofil, Bonesource and Chronos) was significantly higher than from low release cements Biobon and Norian and than low release granules Bonesave and Biosorb. (b)The release from Chronos was also higher than from low release cement Calcibon (all $p<$ 0.05). Only two cements showed continuous release (Biobon and Bonesource for 17 days). For comparison, available gentamicin extracted from samples ground immediately after production is shown in the control column. Values are means \pm SD of at least three experiments in triplicate.

\begin{tabular}{|c|c|c|c|c|c|}
\hline \multirow[t]{2}{*}{ Carrier } & \multicolumn{4}{|c|}{ Gentamicin (mg/g) } & \multirow{2}{*}{$\begin{array}{r}\text { Killing } \\
(\%)\end{array}$} \\
\hline & cumulative release & (\%) & residual & control & \\
\hline \multicolumn{6}{|l|}{ Cements } \\
\hline Biobon & $14.0 \pm 3.6$ & 46.7 & $2.1 \pm 2.1$ & $17.1 \pm 0.0$ & 99.8 \\
\hline Biofil & $23.2 \pm 4.0$ & $77.3^{\mathrm{a}}$ & $0.9 \pm 0.3$ & $21.3 \pm 3.9$ & 99.7 \\
\hline Bonesource & $25.3 \pm 2.5$ & $84.3^{\mathrm{a}}$ & $1.8 \pm 2.0$ & $23.4 \pm 4.5$ & 99.8 \\
\hline Calcibon & $16.1 \pm 5.9$ & 53.7 & $5.8 \pm 3.8$ & $21.2 \pm 0.5$ & 99.8 \\
\hline Chronos & $25.6 \pm 3.3$ & $85.3^{a, b}$ & $0.5 \pm 0.3$ & $22.0 \pm 5.5$ & 99.1 \\
\hline Norian & $10.8 \pm 3.8$ & 36.0 & $6.4 \pm 0.0$ & $16.9 \pm 8.4$ & 99.8 \\
\hline \multicolumn{6}{|c|}{ Granules } \\
\hline Allogran & $15.2 \pm 9.6$ & 50.7 & 0.0 & $16.5 \pm 10.0$ & 99.8 \\
\hline Bicalphos & $13.4 \pm 8.2$ & 44.7 & 0.0 & $15.3 \pm 9.9$ & 99.8 \\
\hline Biosorb & $9.6 \pm 2.7$ & 32.0 & 0.0 & $11.5 \pm 6.0$ & 99.8 \\
\hline Bonesave & $9.1 \pm 5.5$ & 30.3 & 0.0 & $10.0 \pm 4.6$ & 99.7 \\
\hline Cerasorb & $10.8 \pm 7.1$ & 36.0 & 0.0 & $11.1 \pm 7.1$ & 99.8 \\
\hline Vitoss & $18.6 \pm 8.3$ & 62.0 & 0.0 & $18.6 \pm 10.1$ & 99.4 \\
\hline
\end{tabular}

nine samples per carrier-material. Cements were divided in high release and low release; the threshold was arbitrarily

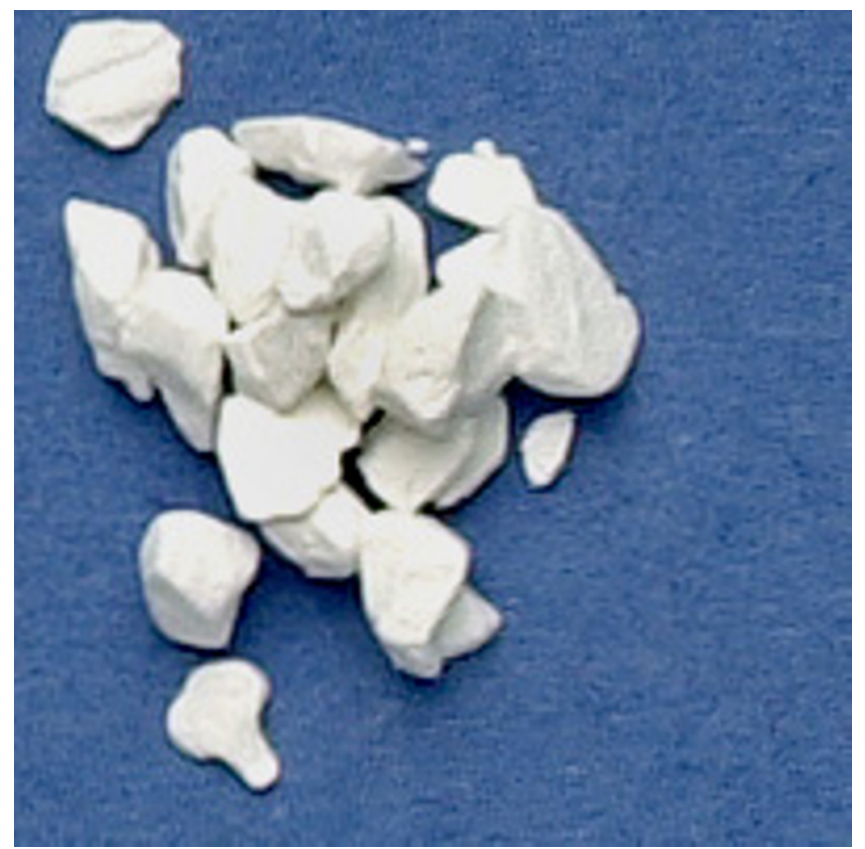

Figure 2

Samples of the granule types illustrate the differences in shape and macro-porosity: Allogran set at $20 \mathrm{mg} / \mathrm{g}$ or $67 \%$ release. Since all granules released $<20 \mathrm{mg} / \mathrm{g}$ this division was not made for granules.

\section{Antimicrobial activity}

A killing assay was used to ascertain gentamicin activity was undiminished by possible interaction with the calcium-phosphate. As described earlier [11], samples of 500 $\mu \mathrm{L}$ release-medium (taken after 24 hours) were freezedried and $10^{6} \mathrm{cfu}$ Staphylococcus aureus ATCC 10834 were added in $100 \mu \mathrm{L}$ of $1 \mathrm{mM}$ potassium-phosphate-buffer (pH 8.0) containing 1.0\% Brain Heart Infusion. After 60 minutes incubation at $37^{\circ} \mathrm{C}$, these were diluted in PBS and quantitatively cultured. The percentage of killing was calculated: [1-(cfu in sample/cfu in control)] $\times 100 \%$, ( $>90 \%$ was considered active). Sterile cultures were conservatively calculated as $99.8 \%$ killing, which was the detection limit of the assay. Samples without GS were used as controls; samples from the first day were used as representative samples for the drug-carrier combination since these all contained sufficient amounts of gentamicin.

\section{Results}

The cumulative release varied from $36 \%$ to $85 \%$ (cements) and 30\% to 62\% (granules) of the GS added during production. High killing percentages (99-100\%) indicated intact antimicrobial activity (Table 1). Figure 1 , 2, 3, 4, 5, 6 and 7 show the cement-cylinders, the mold 


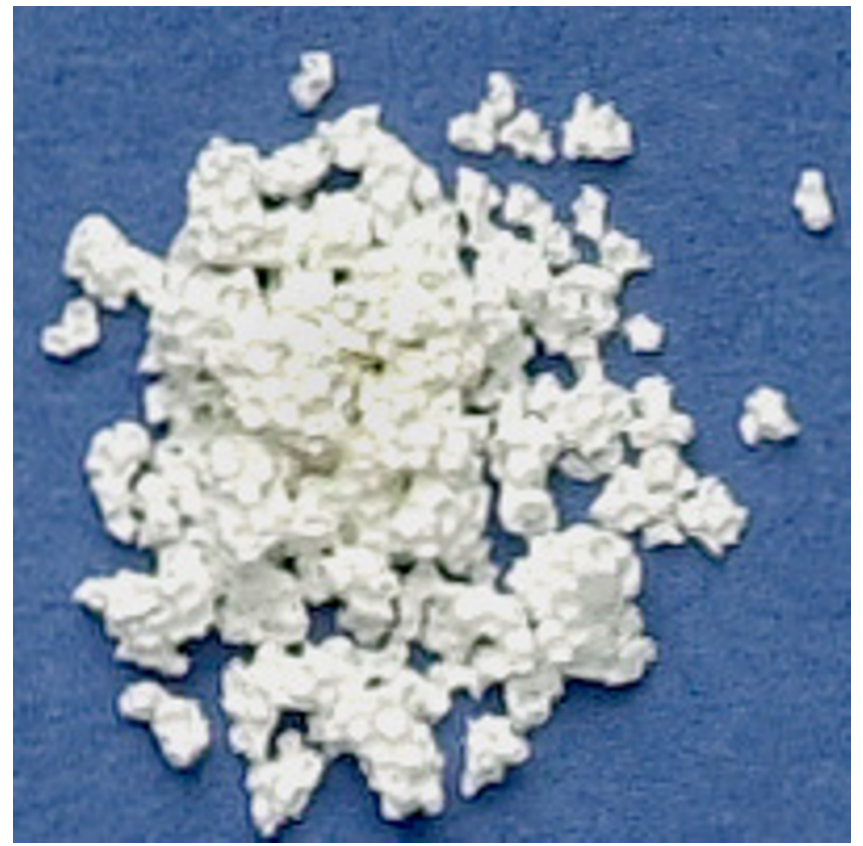

Figure 3

Bicalphos

and the different irregularly porous granule-types. All cements showed burst-release in the first day, two cements (Biobon and Bonesource) showed a continuous-release for 17 days. From all cements residual gentamicin could be extracted, which was highest in Calcibon and Norian (Table 1).

The high release cements (Chronos, Bonesource and Biofil) released more GS than low release cements (Norian and Biobon) and than low release granules Bonesave and Biosorb ( $\mathrm{p}<0.05$, Table 1). The release from Chronos was also higher than from low release cement Calcibon $(\mathrm{p}<0.05)$, the differences between Bonesource, Biofil and Calcibon were not significant. In Figure 8 the release of GS from cements is expressed as a fraction of the total cumulative release. In Figure 9 release results from the granules are plotted. The initial release, both from cements and from granules, follows square-root-of-time kinetics.

The granules all had burst-release during the first day, which was related to the amount of GS that had associated with the carrier-material during production (Table 1, control column). The release from the granules showed a larger variation than from cements, no significant differences between the different granule types were observed. The GS that did not associate with the granules during production was recovered from the vessels in which the samples had been freeze-dried; no residual GS was extracted from the granules.

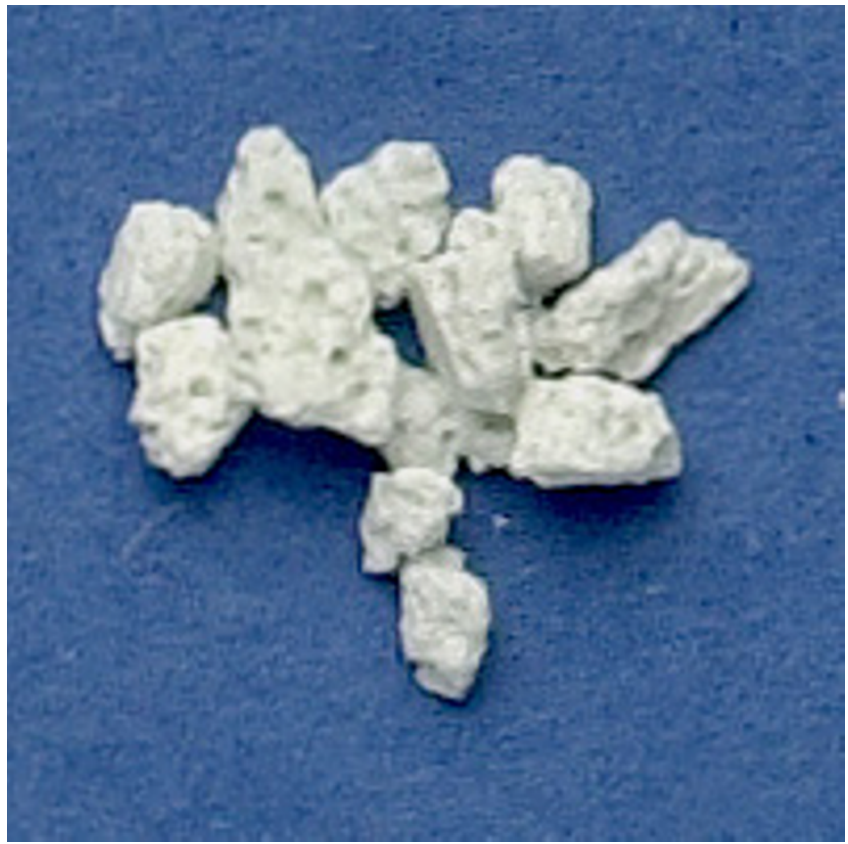

Figure 4

Bonesave

\section{Discussion}

A safe release profile would feature a short duration of antibiotic release after which the release should stop completely to prevent sub-inhibitory gentamicin concentrations, which could induce resistant bacteria [12]. A

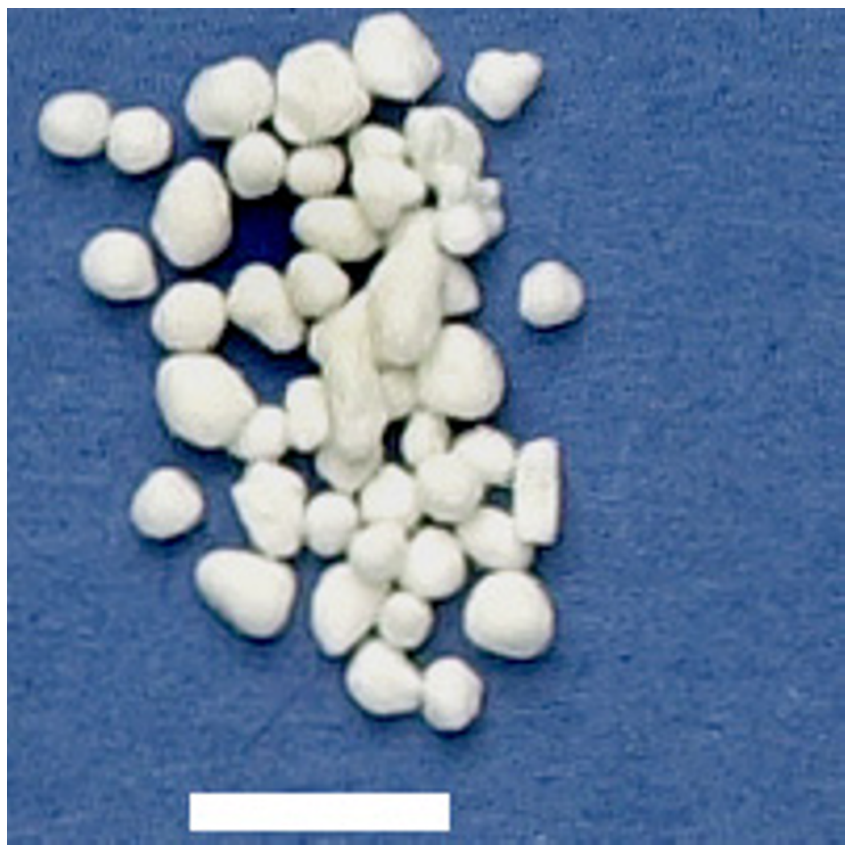

Figure 5

Cerasorb 


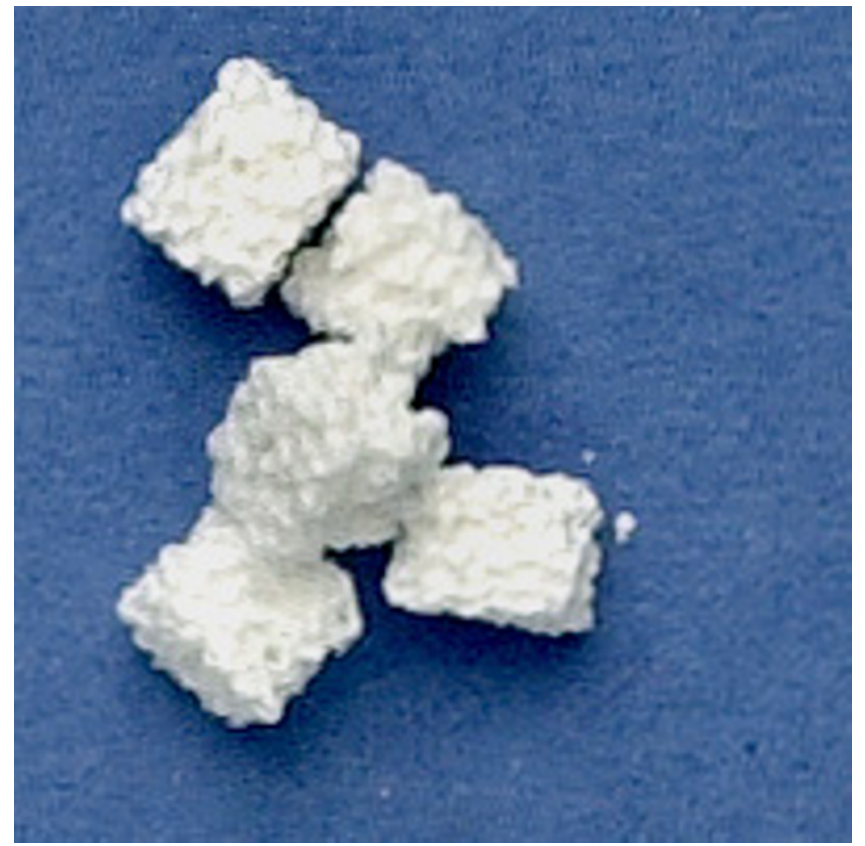

Figure 6

Biosorb

discrete burst after implantation eradicating the contaminating bacteria in the surgical site could be sufficient for prophylactic therapy. This would fit the burst-release seen in all carrier-materials of the current study. The continuous-release profile for 17 days seen in Biobon and Bonesource could conform well with treatment of established osteomyelitis in which a concentration $\geq 8 \mu \mathrm{g} / \mathrm{mL}$ for several weeks has been propagated $[13,14]$.

Remarkably, all twelve carriers showed a higher release of active GS than reported from injectable PMMA cements. The release in the first seven days was $36-78 \%$ for cements and $30-62 \%$ for granules. Based on similar experiments both Kühn and van de Belt reported up to $17 \%$ release after seven days [14-16] Using the same conditions as the current study, Faber and coworkers reported 18\% release from small sized PMMA-cement samples [17].

The GS content is a major determinant of cumulative release. This study used 3.0\%, a review of current antibiotic containing PMMA cements reports a range of 2.3$3.8 \%$. [15] Another important factor is the surface to volume ratio; our study used $6 \times 5 \mathrm{~mm}$ cylinders (diameter $\times$ height). Compared to our study, both Kühn and van de Belt used larger sized samples, which may have influenced the total release $[14,15]$ The importance of carrier size was demonstrated in vivo by Walenkamp; small PMMA-beads established a markedly higher gentamicin release (over $90 \%$ ) than larger ones. [18] In contrast to biodegradable

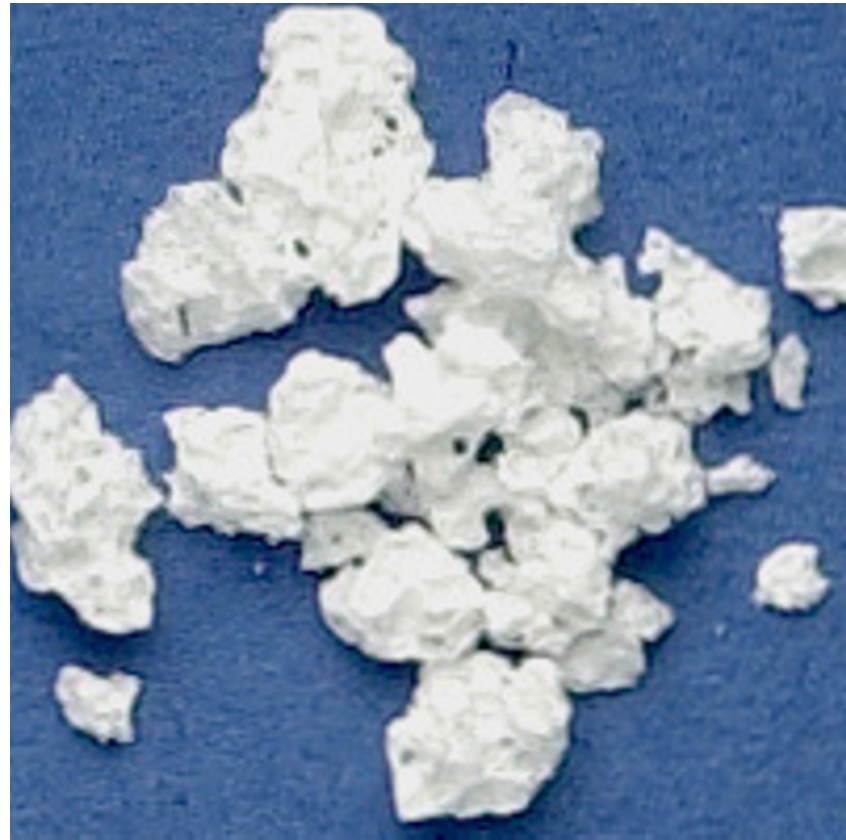

Figure 7

Vitoss

materials, PMMA-beads allow staged treatment and require surgical removal after each treatment episode.

As anticipated, the antimicrobial activity was retained; gentamicin is a heat-stable aminoglycoside and has been shown to release intact from several carrier-materials $[6,19,20]$. From the cements, not all GS could be extracted, suggesting incorporation of gentamicin into the cement. The mechanism could be by interaction of the positively charged gentamicin-base with the calcium-phosphate crystal-structure during the setting reaction $[11,13]$. This interaction could have been of influence on the continuous release seen in Biobon and Bonesource. Some of the (non-released) residual GS was not strongly bound to the cement matrix and could be extracted by grinding the cement samples and high salt concentrations to decrease charge dependant binding. This fraction may have been sequestered in the deeper layers, inaccessible to the release fluid. In vivo, it could cause prolonged release from the carrier during biodegradation, when ingrowing cells and crack formation increase the carrier-surface exposed to extracellular fluid. Carrier-surface characteristics and drug-sequestration appear to significantly influence the release profile; which could be used to tailor the therapeutic effect of drugs [14]. Favourable release properties should result in consistent safe therapeutic drug concentrations. Although all carriers used exist of calcium-phosphate salts, the chemical composition of the individual products differs. This could influence release properties by 


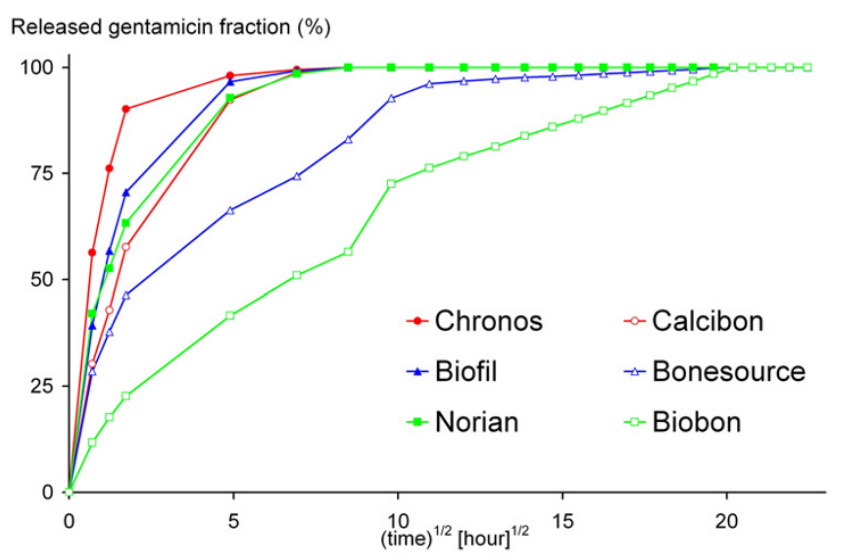

Figure 8

Gentamicin released from biodegradable cements. The cumulative released GS fraction as part of the total release is plotted as a function of the square root of time. Initial release was linear $\left(R^{2}>0.9\right)$. Data represent cumulative values from a complete fluid exchange experiment.

diferences in material characteristics as surface roughness, wettability and chemical reactivity of the surface [14].

The variation in total release was smaller in cements than in granules, possibly indicating that the cement mixing procedure gives a more homogeneous drug-distribution than drug-adsorption onto the irregular porous granulessurface. Both the initial burst from the cements and the complete burst-release from the granules follow squareroot-of-time kinetics (Figures 8 and 9). Such kinetics would indicate that initial release from these carriers is predominantly by diffusion $[13,21]$. This suggests attachment of the drug both to the carrier-surface and to the internal surface of the pores. During preparation, not all GS associated with the granules, indicating that the granules' porosity and surface properties may limit the amount of GS that will attach.

This in vitro study is limited by the extrapolation of the results to clinical concentrations in bone and surrounding tissues. Many different models to analyze drug-release have been described, all optimized for certain factors that influence release including: release medium, fluid exchange volume, flow rate, and interfacial gap [22-24]. In this model testing conditions were rigidly kept constant for all groups, but not all physiological parameters were mimicked: clearance of the drug by blood flow, buffered $\mathrm{pH}$ and ionic content, and the high concentration in the carrier-bone interface were not included in this model [22]. This experiment used complete exchange of small volumes of water as the release medium, allowing com-

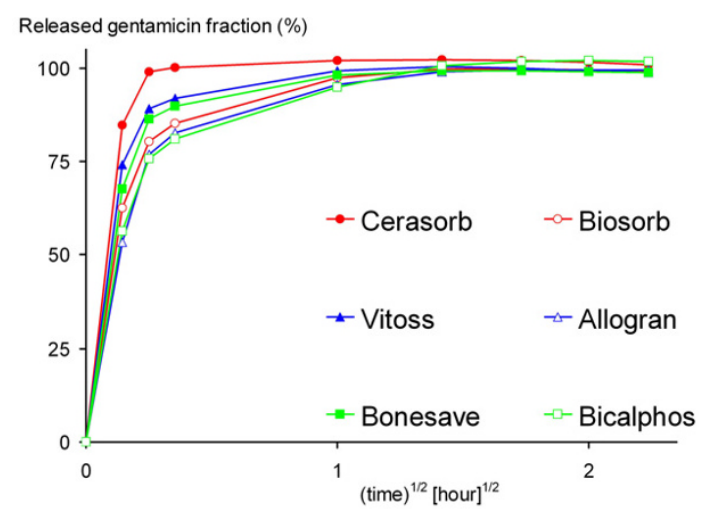

Figure 9

Gentamicin released from biodegradable granules. A burst release pattern was observed in all sample groups.

parison with our earlier experiments that reported dosedependent release of antimicrobial agents from PMMA and biodegradable carriers [10,11]. In animal experiments, we successfully used calcium-phosphate cement loaded with gentamicin to prevent infection in a well characterized rabbit model of osteomyelitis. Bone cultures, the gold standard in osteomyelitis detection, showed a significant reduction in pathogenic bacteria [25]. This stresses the potential therapeutic options of such composites [26]. As a technical advantage, the current set-up will test several combinations in one experimental run, since it accommodates a large number of isolated samples.

The strength of in vitro release studies of this kind lies in a qualitative comparison of different carrier materials, allowing the identification of the most suitable drug-carrier composites. Although recognizing the limitations of in vitro models, a positive correlation between in vivo and in vitro results has been reported for gentamicin-containing biodegradable implants $[27,28]$. This study presents several high release carriers. Possible advantages of cements include high and continuous release and easy injection into the relevant anatomic site. We have succesfully used antibiotic containing cement in small animal models [26]. On the other hand, the granules completely released all gentamicin present, markedly decreasing the risk of inducing antimicrobial resistance.

Prolonged in-hospital systemic antibiotic treatment of osteomyelitis implies a heavy burden for both patient and healthcare organisation. The large number of currently available non-biodegradable antibiotic carriers underscores the demand for sound local antibiotic treatment options. In contrast, only few approved biodegradable antibiotic delivery devices are currently available. This emphasizes the clinical potential of biodegradable antibi- 
otic carriers and the need for comparative studies. By using materials approved for implantation in bone, the gap between pre-clinical and clinical studies may perhaps be narrowed, thus allowing early adaptation and implementation of these devices.

\section{Conclusion}

For patients requiring surgery for bone defects, the burstrelease pattern observed in all carriers, may offer clinical applications for the prevention of osteomyelitis. The prolonged release-profile from two of the cements might be an effective option in the concept of treating osteomyelitis $[8,29]$. Since all carrier-materials are commercially available, these results may readily be extended to in vivo studies to determine the optimal combination for different clinical situations. The presented results support the ongoing clinical exploration of antibiotic containing biodegradable drug-delivery systems $[5,19,26]$.

\section{Competing interests}

This study was made possible by Senter Grant TSGE 1044 and AM-Pharma BV (Bunnik, the Netherlands).

\section{Authors' contributions}

HS and CF were the primary researchers, AB supervised the experiments, worked on data processing and writing. PW and AA were the directors of the study. All authors read and approved the final manuscript.

\section{Acknowledgements}

The authors are grateful to Dirk-Jan Bervoets and Jolanda de Blieck-Hogervorst for their assistance with the release experiments. The gentamicin determinations were performed at the VU University Medical Center, department Pharmacy.

\section{References}

I. Cierny GIII, Mader JT, Penninck J]: A clinical staging system for adult osteomyelitis. Clin Orthop Relat Res 2003:7-24.

2. Le Saux N, Howard A, Barrowman NJ, Gaboury I, Sampson M, Moher $D$ : Shorter courses of parenteral antibiotic therapy do not appear to influence response rates for children with acute hematogenous osteomyelitis: a systematic review. BMC Infect Dis 2002, 2:16.

3. Henry SL, Galloway KP: Local antibacterial therapy for the management of orthopaedic infections. Pharmacokinetic considerations. Clin Pharmacokinet 1995, 29:36-45.

4. Neut $D$, van de Belt $H$, Stokroos I, van Horn JR, van der Mei HC, Busscher HJ: Biomaterial-associated infection of gentamicinloaded PMMA beads in orthopaedic revision surgery. J Antimicrob Chemother 200I, 47:885-89I.

5. Walenkamp GH: Gentamicin PMMA beads and other local antibiotic carriers in two-stage revision of total knee infection: a review. J Control Release 200I, I 3 Spec No I:66-72.

6. Wichelhaus TA, Dingeldein E, Rauschmann M, Kluge S, Dieterich R, Schafer $V$, Brade V: Elution characteristics of vancomycin, teicoplanin, gentamicin and clindamycin from calcium sulphate beads. J Antimicrob Chemother 2001, 48: I I7- I I9.

7. Humphrey JS, Mehta S, Seaber AV, Vail TP: Pharmacokinetics of a degradable drug delivery system in bone. Clin Orthop Relat Res 1998:218-224.

8. Nijhof MW, Stallmann HP, Vogely HC, Fleer A, Schouls LM, Dhert WJ, Verbout AJ: Prevention of infection with tobramycin-con- taining bone cement or systemic cefazolin in an animal model. J Biomed Mater Res 2000, 52:709-7I5.

9. Blokhuis TJ, Termaat MF, den Boer FC, Patka P, Bakker FC, Haarman $\mathrm{HJ}$ : Properties of calcium phosphate ceramics in relation to their in vivo behavior. J Trauma 2000, 48: $179-186$.

10. Faber C, Stallmann HP, Lyaruu DM, de Blieck JM, Bervoets TJ, Nieuw Amerongen AV, Wuisman PI: Release of antimicrobial peptide Dhvar-5 from polymethylmethacrylate beads. I Antimicrob Chemother 2003, 5 I: I359-I364.

II. Stallmann HP, Faber C, Slotema ET, Lyaruu DM, Bronckers AL, Nieuw Amerongen AV, Wuisman PI: Continuous-release or burst-release of the antimicrobial peptide human lactoferrin I-I I (hLFI-II) from calcium phosphate bone substitutes. J Antimicrob Chemother 2003, 52:853-855.

12. van de Belt $H$, Neut D, van Horn JR, van der Mei HC, Schenk W, Busscher HJ: Antibiotic Resistance - to treat or not to treat? Nat Med 1999, 5:358-359.

13. Bohner M, Lemaitre J, Van Landuyt P, Zambelli PY, Merkle HP, Gander B: Gentamicin-loaded hydraulic calcium phosphate bone cement as antibiotic delivery system. J Pharm Sci 1997, 86:565-572.

14. van de Belt $H$, Neut D, Uges DR, Schenk W, van Horn JR, van der Mei $\mathrm{HC}$, Busscher HJ: Surface roughness, porosity and wettability of gentamicin-loaded bone cements and their antibiotic release. Biomaterials 2000, 21 : 1981-1987.

15. Kühn KD: Bone cements : up-to-date comparison of physical and chemical properties of commercial materials Springer, London, UK; 2000.

16. van de Belt $H$, Neut $D$, Schenk $W$, van Horn JR, van der Mei HC, Busscher HJ: Gentamicin release from polymethylmethacrylate bone cements and Staphylococcus aureus biofilm formation. Acta Orthop Scand 2000, 71:625-629.

17. Faber C, Hoogendoorn RJ, Lyaruu DM, Stallmann HP, van Marle J, Nieuw Amerongen AV, Smit TH, Wuisman PI: The effect of the antimicrobial peptide, Dhvar-5, on gentamicin release from a polymethyl methacrylate bone cement. Biomaterials 2005, 26:5717-5726.

18. Walenkamp G: Small PMMA beads improve gentamicin release. Acta Orthop Scand 1989, 60:668-669.

19. Ipsen T, Jorgensen PS, Damholt V, Torholm C: Gentamicin-collagen sponge for local applications. 10 cases of chronic osteomyelitis followed for I year. Acta Orthop Scand I991, 62:592-594.

20. Soriano I, Evora C: Formulation of calcium phosphates/poly (d,I-lactide) blends containing gentamicin for bone implantation. J Control Release 2000, 68: I2I-I34.

21. Higuchi T: Mechanism of sustained-action medication. Theoretical analysis of rate of release of solid drugs dispersed in solid matrices. J Pharm Sci 1963, 52: | | 45- | | 49.

22. Hendriks JG, Neut D, van Horn JR, van der Mei HC, Busscher HJ: The release of gentamicin from acrylic bone cements in a simulated prosthesis-related interfacial gap. J Biomed Mater Res 2003, 64B: $1-5$.

23. McLaren AC, McLaren SG, Nelson CL, Wassell DL, Olsen KM: The effect of sampling method on the elution of tobramycin from calcium sulfate. Clin Orthop 2002:54-57.

24. Perry AC, Rouse MS, Khaliq Y, Piper KE, Hanssen AD, Osmon DR, Steckelberg JM, Patel R: Antimicrobial release kinetics from polymethylmethacrylate in a novel continuous flow chamber. Clin Orthop 2002:49-53.

25. Zuluaga AF, Galvis W, Jaimes F, Vesga O: Lack of microbiological concordance between bone and non-bone specimens in chronic osteomyelitis: an observational study. BMC Infect Dis 2002, 2:8

26. Stallmann HP, Faber C, Bronckers AL, Nieuw Amerongen AV, Wuisman $\mathrm{PI}$ : Osteomyelitis prevention in rabbits using antimicrobial peptide hLFI-II- or gentamicin-containing calcium phosphate cement. J Antimicrob Chemother 2004, 54:472-476.

27. Baro M, Sanchez E, Delgado A, Perera A, Evora C: In vitro-in vivo characterization of gentamicin bone implants. J Control Release 2002, 83:353.

28. Torrado S, Frutos P, Frutos G: Gentamicin bone cements: characterisation and release (in vitro and in vivo assays). Int $J$ Pharm 200I, 2 I 7:57-69.

29. Nelson CL, McLaren SG, Skinner RA, Smeltzer MS, Thomas JR, Olsen $\mathrm{KM}$ : The treatment of experimental osteomyelitis by surgical debridement and the implantation of calcium sulfate tobramycin pellets. J Orthop Res 2002, 20:643-647. 


\section{Pre-publication history}

The pre-publication history for this paper can be accessed here:

http://www.biomedcentral.com/1471-2474/7/18/prepub

Publish with Bio Med Central and every scientist can read your work free of charge

"BioMed Central will be the most significant development for disseminating the results of biomedical research in our lifetime. " Sir Paul Nurse, Cancer Research UK

Your research papers will be:

- available free of charge to the entire biomedical community

- peer reviewed and published immediately upon acceptance

- cited in PubMed and archived on PubMed Central

- yours - you keep the copyright 